\title{
Knowledge and Awareness towards Chronic Kidney Disease Risk Factors in Saudi Arabia
}

\author{
Ibrahim A. Bin Ahmed', Saleh Hadi Alharbi', Fahad A. Alateeq1, Abdulmalik M. Aloriney', \\ Abdullah Abdulhadi Hammad Alharbi², Abdul Rahman Ali AlSogair², \\ Ali Dawood Mohmmed Almansour², Alanoud Mansour Ayed Albalawi², \\ Hussain Gadelkarim Ahmed ${ }^{2}$
}

${ }^{1}$ Faculty of Medicine, Al Imam Mohammad ibn Saud Islamic University, Riyadh, Saudi Arabia

${ }^{2}$ College of Medicine, University of Hail, Hail, Saudi Arabia

Email: hussaingad5@gmail.com

How to cite this paper: Ahmed, I.A.B., Alharbi, S.H., Alateeq, F.A., Aloriney, A.M., Alharbi, A.A.H., AlSogair, A.R.A., Almansour, A.D.M., Albalawi, A.M.A. and Ahmed, H.G. (2018) Knowledge and Awareness towards Chronic Kidney Disease Risk Factors in Saudi Arabia. International Journal of Clinical Medicine, 9, 799-808.

https://doi.org/10.4236/ijcm.2018.911066

Received: October 11, 2018

Accepted: November 10, 2018

Published: November 13, 2018

Copyright $\odot 2018$ by authors and Scientific Research Publishing Inc. This work is licensed under the Creative Commons Attribution International License (CC BY 4.0).

http://creativecommons.org/licenses/by/4.0/

\section{(c) (i) Open Access}

\begin{abstract}
Background: The risk of CKD is high in Saudi Arabia due to increasingly growing prevalence of its risk factors, such as diabetes, hypertension and obesity. Therefore, the objective of this study was to assess the level of awareness of Saudi population towards CKD risk factors in order to generate platform for future planning. Methodology: This study included 940 apparently healthy Saudi volunteers, their ages ranging from 17 to 65 years old with a mean age of 35 years. A purposeful questionnaire was designed and used for obtaining data about the CKD risk factors. Results: Out of 940 participants, 293 (31.2\%) were males and 647 (68.8\%) were females, giving males "females" ratio of 1.00:2.21. About $62.3 \%$ of the participants were found to believe that $\mathrm{DM}$ is one of the main risk factors for $\mathrm{CKD}$, of whom, $74 \%$ were males and $57 \%$ were females. Approximately $60 \%$ of the participants were found believing that hypertension is one of the main risk factors for CKD, of whom $79.5 \%$ were males and $51.6 \%$ were females. Conclusion: There is an increasing in the prevalence of CKD risk factors among Saudi population. Although, the levels of awareness toward some CKD risk factors are relatively increasing, but more health education efforts are deemed importance.
\end{abstract}

\section{Keywords}

CKD, Saudi Arabia, Hypertension, Diabetes, Obesity, Awareness, Risk Factors

\section{Introduction}

Chronic kidney disease (CKD) is an evolving worldwide public health concern 
[1]. CKD witnessed a rapid increase from $36^{\text {th }}$ as leading cause of death in 1990 to the $19^{\text {th }}$ leading cause in 2013 [2]. CKD is associated with many predisposing medical conditions, with most encountered are hypertension (HTN) and diabetes mellitus (DM) [3]. A transformation in the global approach to CKD from the treatment of end stage renal disease (ESRD) to meticulous primary and secondary prevention is so deliberated a complete public health urgency [4].

Risk factors for the development of CKD, mainly chronic kidney failure, would encompass susceptibility factors and initiation factors [5]. Prevention of adverse outcomes of CKD could be simplified by assessing persons with risk factors, to allow earlier detection, and by risk factor lessening in persons without $\mathrm{CKD}$, to prevent or slow the development of the disease. The difficulty of detecting the early stages of CKD makes it challenging to decide whether the risk factors so far recognized relate more to susceptibility, initiation, or progression [6]. HTN, DM, obesity, smoking, Exposure to heavy metals, excessive alcohol consumption, smoking, and the use of non-steroidal anti-inflammatory analgesic drug (NSAID) medications, kidney injury, a history of cardiovascular disease (CVD), hyperlipidemia, metabolic syndrome, hepatitis C virus, HIV infection, and malignancy are the most frequent debated CKD risk factors. An uncontrolled DM and/or HTN can easily and rapidly progress to ESRD [7].

CKD prevalence is high in Saudi Arabia; therefore, preventive interventions are highly recommended, since, CKD prevalence is likely to rise over the next decades due to increase of its risk factors [8].

In a survey for CKD employing household visits, in northern Saudi Arabia, high percentages of risk factors were indicated in a family history (FH) of DM representing $72 \%$, followed by family history of HTN, recurrent urinary tract infection, DM, family history of renal disease, HTN, and NSAID analgesic abuse, constituting $65 \%, 59 \%, 26 \%, 26 \%, 25 \%$, and $22 \%$, respectively [6]. One of the essential steps towards CKD prevention and control is raising the CKD awareness and increasing health related knowledge among general population. Therefore, the objective of this study was to assess the level of awareness of Saudi population towards CKD risk factors in order to generate platform for future planning.

\section{Materials and Methods}

In this longitudinal descriptive study, data were obtained from 940 Saudi volunteers living in the city of Hail, the Kingdom of Saudi Arabia (KSA). Participants were randomly selected by simple random method regardless of their age, gender or education level.

Purposeful questionnaire was designed and used for collection of the required data. The following information were obtained from each participant: age, sex, occupation, education level, DM, HTN, Obesity, Hereditary factors, cardiovascular disease, Family history of kidney disease and NSAID analgesics usage.

\subsection{Data Analysis}

Statistical Package for Social Sciences (SPSS) was used for analysis and to perform 
Pearson Chi-square test for statistical significance (P value). The $95 \%$ confidence level and confidence intervals were used. $P$ value less than 0.05 was considered statistically significant.

\subsection{Ethical Consent}

Each participant was asked to sign a written ethical consent during the interview to obtain the information. The informed ethical consent form was designed and approved by the ethical committee of the College of Medicine (University of Hail, KSA) Research Board.

\section{Results}

This study included 940 volunteers their ages ranging from 17 to 66 years old with a mean age of 35 years. Out of 940 participants, 293 (31.2\%) were males and 647 (68.8\%) were females, giving males':females' ratio of 1.00:2.21.

Table 1 and Figure 1 summarize the distribution of the study subjects by demographical features. The majority of the study subjects were found at age range 19 - 25 years constituting 348 (37\%) followed by age groups $45-55, \leq 18$, and $\geq 56$ years constituting 179 (19\%), 157 (16.7\%) and 145 (15.4\%), correspondingly. The majority of participants were found with basic education level, were found at age group $\geq 56$ and 45 - 55 years old, representing 30/52 (57.7\%), and

Table 1. Distribution of the study subjects by demographical features.

\begin{tabular}{|c|c|c|c|c|c|}
\hline Variable & Category & Basic edu & Secondary edu & University & Total \\
\hline \multicolumn{6}{|l|}{ Age } \\
\hline & $\leq 18$ years & 0 & 157 & 0 & 157 \\
\hline & $19-25$ & 0 & 0 & 348 & 348 \\
\hline & $26-34$ & 0 & 16 & 26 & 42 \\
\hline & $35-44$ & 0 & 24 & 45 & 69 \\
\hline & $45-55$ & 25 & 179 & 0 & 179 \\
\hline & $\geq 56$ & 27 & 86 & 7 & 145 \\
\hline & Total & 52 & 462 & 426 & 940 \\
\hline \multicolumn{6}{|l|}{ Occupation } \\
\hline & Teacher & 0 & 106 & 92 & 198 \\
\hline & Military & 22 & 2 & 50 & 74 \\
\hline & Free work & 30 & 0 & 32 & 62 \\
\hline & Student & 0 & 151 & 252 & 403 \\
\hline & Other & 0 & 203 & 0 & 203 \\
\hline & Total & 52 & 462 & 426 & 940 \\
\hline \multicolumn{6}{|l|}{ Gender } \\
\hline & Males & 22 & 163 & 108 & 293 \\
\hline & Females & 30 & 299 & 318 & 647 \\
\hline & Total & 52 & 462 & 426 & 940 \\
\hline
\end{tabular}




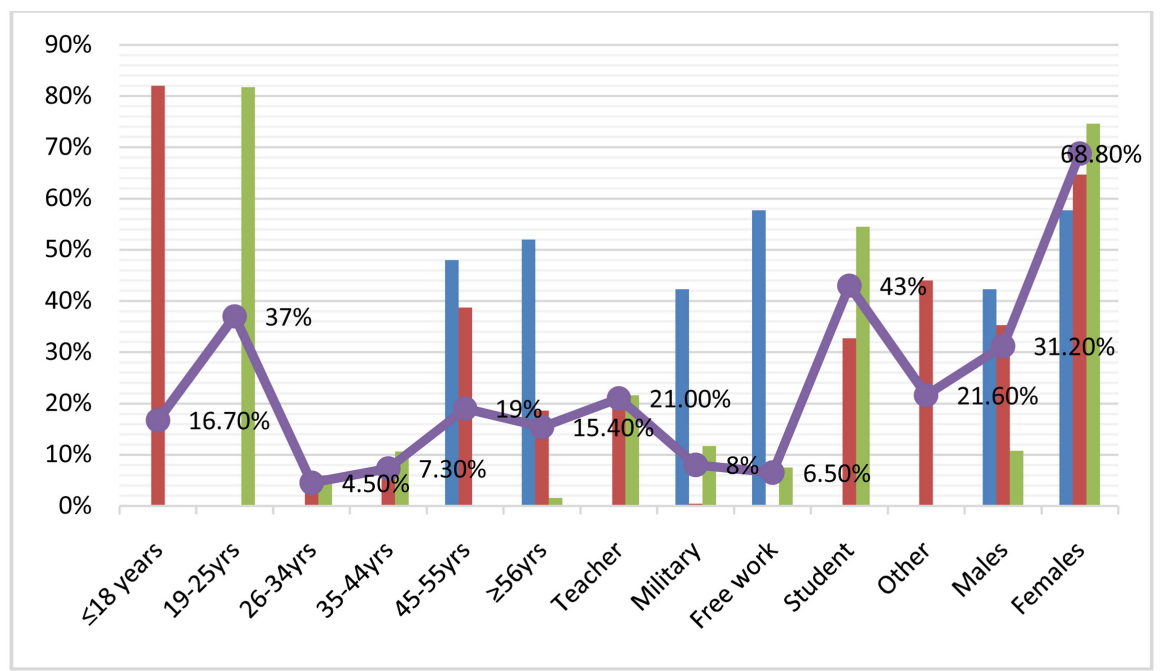

Figure 1. Description of the study population by demographical characteristics.

22/52 (43.3\%), respectively, out of the total number of participants with basic education. The majority of participants with secondary education level were found at age group 45 - 55 and $\leq 18$ years, representing 179/462 (38.7\%), and $157 / 462$ (34\%), respectively, of the total participants with secondary education. The majority of participants with university level were found at age group 19 25 and 35 - 44 years, representing 348/426 (81.7\%), and 45/426 (10.6\%), respectively, of the total participants with secondary education, as described in Table 1 and Figure 1.

With regard to the occupation, most of the participants were students followed by teachers constituting 403/940 (42.9\%), and 198/940 (21\%), respectively. For those with basic education, the majority were found among free work followed by military representing 30/52 (57.7\%), and 22/52 (43.3\%), in this order. For those with secondary education, most of them were found amongst students followed by teachers representing 203/462 (44\%), and 106/462 (23\%), in this order. For those with university education, most of them were students followed by teachers representing $252 / 426$ (59\%), and $92 / 426$ (21.6\%), in this order, as described in Table 1 and Figure 1.

With regard to gender, females were found with greater number in basic education, secondary education and university representing 30/52 (57.7\%), 299/462 (64.7\%) and 318/426 (74.6\%) respectively, as described in Table 1 and Figure 1.

About 128/940 (13.6\%) of the participants were found to be diabetic, of whom 57/293 (19.5\%) were males and 71/647 (11\%) were females. Moreover, around $87 / 940$ (9.3\%) of the participants were found hypertensive, of whom 58/293 (20\%) were males and 29/647 (4.5\%) were females, as indicated in Table 2 and Figure 2 .

Table 3 summarizes the distribution of the study population by the main CKD risk factors according to participants' opinion. About 586/940 (62.3\%) of the participants were found to believe that DM is one of the main risk factors for CKD, of whom 217/293 (74\%) were males and 369/647 (57\%) were females. 
Table 2. Distribution of the study population by DM and HTN status.

\begin{tabular}{ccccc}
\hline Variable & Category & Males & Females & Total \\
\hline DM & Yes & 57 & 71 & 128 \\
& No & 236 & 576 & 812 \\
& Total & 293 & 647 & 940 \\
HTN & & & & \\
& Yes & 58 & 29 & 87 \\
& No & 235 & 618 & 853 \\
& Total & 293 & 647 & 940 \\
\hline
\end{tabular}

Table 3. Distribution of the study population by main CKD risk factors according to participants' opinion.

\begin{tabular}{|c|c|c|c|c|}
\hline Variable & Category & Males & Females & Tota \\
\hline \multicolumn{5}{|l|}{$\mathrm{DM}$} \\
\hline & Yes & 217 & 369 & 586 \\
\hline & No & 76 & 278 & 354 \\
\hline & Total & 293 & 647 & 940 \\
\hline \multicolumn{5}{|l|}{ HTN } \\
\hline & Yes & 233 & 334 & 567 \\
\hline & No & 60 & 313 & 373 \\
\hline \multicolumn{5}{|c|}{ Hereditary (genes) } \\
\hline & Yes & 106 & 285 & 391 \\
\hline & No & 187 & 362 & 549 \\
\hline \multicolumn{5}{|l|}{ Obesity } \\
\hline & Yes & 266 & 578 & 844 \\
\hline & No & 27 & 69 & 96 \\
\hline \multicolumn{5}{|l|}{ CVD } \\
\hline & Yes & 86 & 253 & 339 \\
\hline & No & 207 & 394 & 601 \\
\hline \multicolumn{5}{|c|}{ NSAID Analgesic } \\
\hline & Yes & 230 & 540 & 770 \\
\hline & No & 63 & 107 & 170 \\
\hline \multicolumn{5}{|c|}{ Family history } \\
\hline & Yes & 186 & 103 & 289 \\
\hline & No & 107 & 544 & 651 \\
\hline
\end{tabular}

Approximately $567 / 940$ (60\%) of the participants believed that HTN is one of the main risk factors for CKD, of whom 233/293 (79.5\%) were males and $334 / 647$ (51.6\%) were females. About 391/940 (41.6\%) of the participants believed that hereditary factor is one of the main risk factors for $\mathrm{CKD}$, of whom 106/293 (36\%) were males and 285/647 (44\%) were females. About 844/940 


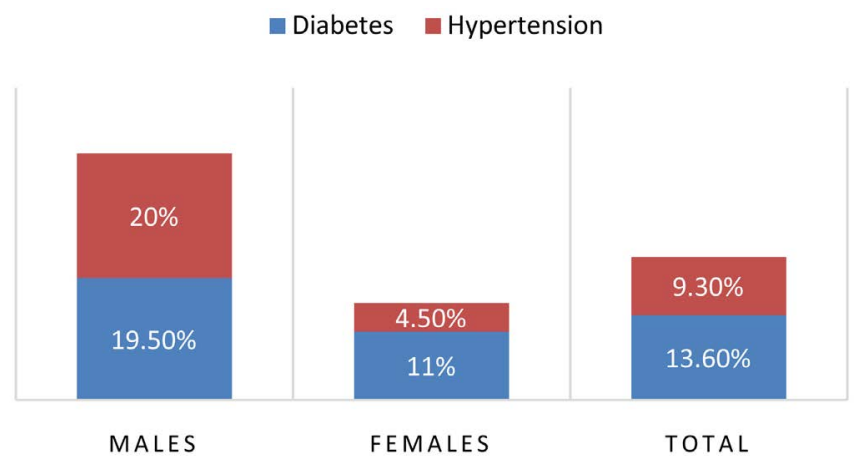

Figure 2. Description of the study population by DM and HTN.

(90\%) of the participants believed that obesity is one of the main risk factors for CKD, of whom 266/293 (91\%) were males and 578/647 (89\%) were females. About 339/940 (36\%) of the participants believed that CVD is one of the main risk factors for CKD, of whom 86/293 (29.4\%) were males and 253/647 (39\%) were females. About 770/940 (82\%) of the participants believed that NSAID analgesic is one of the main risk factors for CKD, of whom 230/293 (78.5\%) were males and 540/647 (83.6\%) were females. About 289/940 (30.7\%) of the participants believed that family history of renal failure is one of the main risk factors for CKD, of whom186/293 (63.5\%) were males and 103/647 (16\%) were females, as shown in Figure 3.

Table 4 summarizes the distribution of the study population by the secondary CKD risk factors according to participants' opinion. About 908/940 (97\%) of the participants were found to believe that nutritional factor is one of the main risk factors for CKD, of whom 279/293 (95\%) were males and 629/647 (97\%) were females. About 527/940 (56\%) of the participants believed that salt is one of the main risk factors for CKD, of whom 231/293 (79\%) were males and 296/647 (46\%) were females. About 404/940 (43\%) of the participants believed that meat is one of the main risk factors for CKD, of whom123/293 (42\%) were males and 281/647 (43\%) were females. About 767/940 (82\%) of the participants believed that tobacco smoking is one of the main risk factors for CKD, of whom 208/293 (71\%) were males and 559/647 (86\%) were females. About $678 / 940(72 \%)$ of the participants believed that alcohol is one of the main risk factors for CKD, of whom 137/293 (47\%) were males and 541/647 (84\%) were females, as shown in Figure 4.

\section{Discussion}

Increased identifying of individuals with undetected CKD or CKD at early stages or those at risk of developing CKD might be more frequent among populations with high levels of awareness towards kidney related diseases. Thus the present study was aiming at exploring Saudi population awareness towards CKD risk factors.

The present study surveyed a population with diverse demographical characteristics, though the number of females was more than males. However, about 


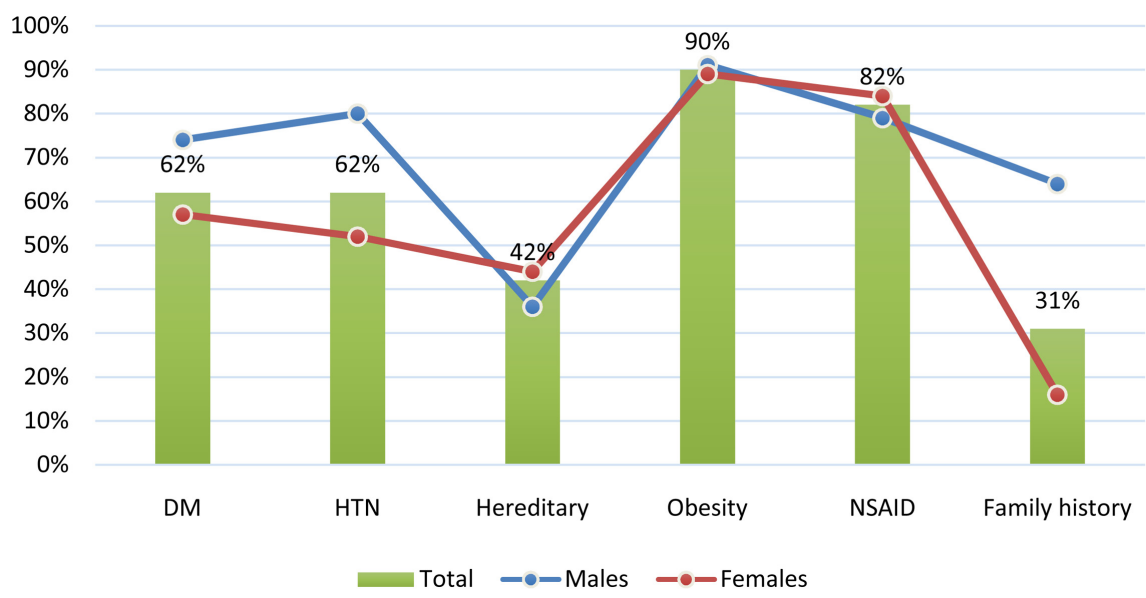

Figure 3. Description of participants, who believed that these are the main risk factors for CKD.

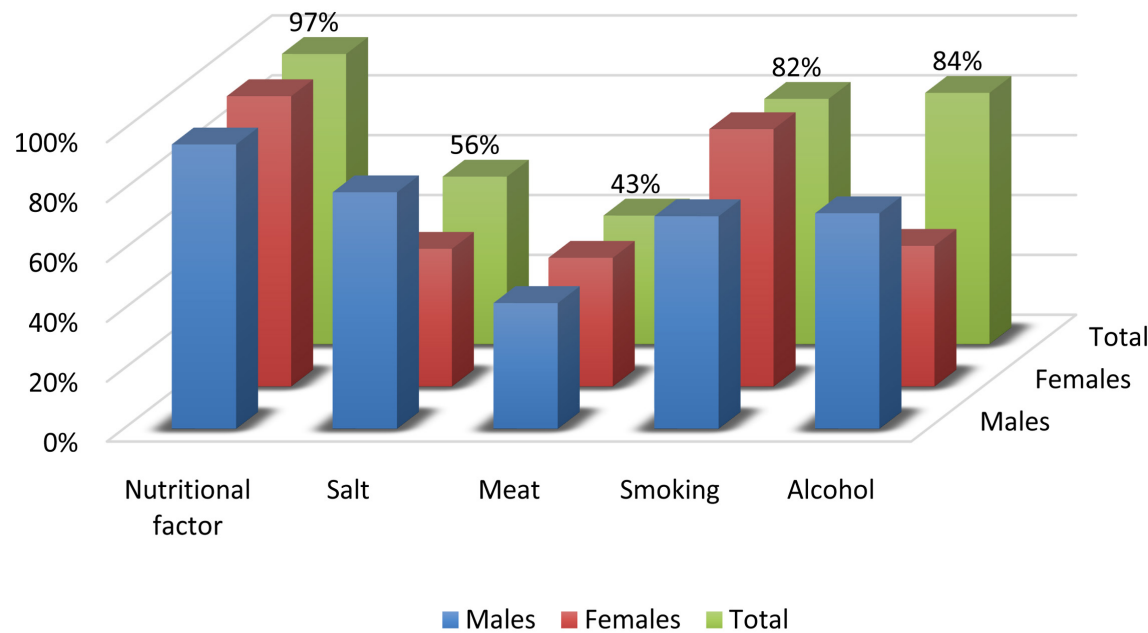

Figure 4. Description of participants, who believed that these are co-risk factors for CKD.

$13.6 \%$ of the participants were found to be diabetic, of whom $19.5 \%$ were males and $11 \%$ were females. It was previously reported in a large survey from the northern Saudi, the prevalence of DM was 27\% [9]. Consequently, such prevalence is expected in randomized samples. Moreover, it was reported that the prevalence of DM in general Saudi population was 30\%. The prevalence of DM was $34.1 \%$ in males and $27.6 \%$ in females $(p<0.0001)$ [10].

In the current study, around $9.3 \%$ of the participants were found hypertensive, of whom $20 \%$ were males and $4.5 \%$ were females. In a comprehensive survey (included 5000 persons) from northern Saudi, the overall prevalence of hypertension was $30.2 \%$. The prevalence of male was $30.8 \%$ and female was $29.6 \%$. The risk of hypertension increases with the increase of age, as well as, with increasing of body mass index (BMI) and this was found to be statistically significant $p<0.0001$ [11].

In the present study about $62.3 \%$ of the participants believed that DM is one of the main risk factors for CKD, of whom $74 \%$ were males and $57 \%$ were 
Table 4. Distribution of the study population by secondary CKD risk factors according to participants' opinion.

\begin{tabular}{ccccc}
\hline Variable & Category & Males & Females & Total \\
\hline Nutritional factor & Yes & 279 & 629 & 908 \\
& No & 14 & 18 & 32 \\
& Total & 293 & 647 & 940 \\
Salt & Yes & 231 & 296 & 527 \\
& No & 62 & 351 & 413 \\
Meat & Yes & 123 & 281 & 404 \\
& No & 170 & 366 & 536 \\
Smoking & Yes & 208 & 559 & 767 \\
& No & 58 & 88 & 173 \\
& & & & \\
Alcohol & Yes & 137 & 541 & 678 \\
& No & 156 & 106 & 262 \\
\hline
\end{tabular}

females. With absence of such data from Saudi Arabia, these findings may indicate a relatively higher awareness level toward DM as a risk factor for CKD, particularly among males. This is similarly the situation for hypertension, approximately $60 \%$ of the participants believed that HTN is one of the main risk factors for $\mathrm{CKD}$, of whom $79.5 \%$ were males and $51.6 \%$ were females.

In the present study about $41.6 \%$ of the participants believed that hereditary factor is one of the main risk factors for CKD, of whom 36\% were males and $44 \%$ were females. According to our personal contact, in the Saudi community, many people think that renal diseases, particularly those associated with kidney failure are hereditary.

On the other hand, about $90 \%$ of the participants believed that obesity is one of the main risk factors for CKD, of whom $91 \%$ were males and $89 \%$ were females. A study form Saudi Arabia has reported that the overall prevalence of obesity was $63.6 \%$ and the prevalence of males was $56.2 \%$ and the prevalence of females was 71\% [12]. The increased consumption of fast foods and sugar dense beverages (e.g., sodas) as well as the extensive use of cars, elevators, escalators, and remotes in recent years has dramatically increased the burden of obesity in KSA. Thus the increased prevalence rate of obesity in the present study indicates the magnitude of the problem in relation to daily life-style. According to Forbes, Saudi Arabia ranks 29 on a 2007 list of the fattest countries with a percentage of $63.5 \%$ of its citizens being overweight $(\mathrm{BMI}>25)$ [13].

Furthermore, about $36 \%$ of the participants in this study believed that cardiovascular disease (CVD) is one of the main risk factors for CKD, of whom $29.4 \%$ were males and 39\% were females. In a recent study from Saudi Arabia to assess 
the level of risk for CVD among young Saudi women, only 15\% of the sample were free of risk factors, the majority had either one (57.5\%) or two $(20.8 \%)$ risk factors. Additionally, $6.7 \%$ were considered to be at high-risk with three or more risk factors. The most common risk factors were physical inactivity (74\%) and overweight/obesity (25\%/29\%) [14].

About $82 \%$ of the participants in the present study believed that nonsteroidal anti-inflammatory (NSAID) analgesic is one of the main risk factors for CKD, of whom $78.5 \%$ were males and $83.6 \%$ were females. Although, this is very high percentage of awareness, but there is an extensive use of NSAID among Saudi population. The top utilized medication class in Saudi Arabia was analgesics specifically diclofenac with different brands from local and international companies. This class represents 67\% of the top used drugs in Saudi Arabia [15].

Moreover, in the present study, the levels of awareness toward some secondary risk factors such salt, meat, smoking and alcohol consumption were variable since these factors are known to contribute to several chronic diseases.

\section{Acknowledgements}

Authors would like to thank Tamam Zamil Mutni Alshammari and Osama Saud H. Aljameel, for their assistance in data acquisition.

\section{Conflicts of Interest}

The authors declare no conflicts of interest regarding the publication of this paper.

\section{References}

[1] Levey, A.S., Atkins, R., Coresh, J., et al. (2007) Chronic Kidney Disease as a Global Public Health Problem: Approaches and Initiatives-A Position Statement from Kidney Disease Improving Global Outcomes. Kidney International, 72, 247-259. https://doi.org/10.1038/sj.ki.5002343

[2] GBD 2013 Mortality and Causes of Death Collaborators (2015) Global, Regional, and National Age-Sex Specific All-Cause and Cause-Specific Mortality for 240 Causes of Death, 1990-2013: A Systematic Analysis for the Global Burden of Disease Study 2013. Lancet, 385, 117-171. https://doi.org/10.1016/S0140-6736(14)61682-2

[3] Abd ElHafeez, S., Bolignano, D., D’Arrigo, G., Dounousi, E., Tripepi, G. and Zoccali, C. (2018) Prevalence and Burden of Chronic Kidney Disease among the General Population and High-Risk Groups in Africa: A Systematic Review. BMJ Open, 8, e015069. https://doi.org/10.1136/bmjopen-2016-015069

[4] El Nahas, A.M. and Bello, A.K. (2005) Chronic Kidney Disease: The Global Challenge. Lancet, 365, 331-340. https://doi.org/10.1016/S0140-6736(05)17789-7

[5] (1996) 27th Bethesda Conference. Matching the Intensity of Risk Factor Management with the Hazard for Coronary Disease Events. September14-15, 1995. Journal of the American College of Cardiology, 27, 957-1047.

[6] Ginawi, I.A., Ahmed, H.G., Ashankyty, I.M., et al. (2013) Survey for Potential Risk Factors for Susceptibility to Chronic Kidney Disease in Hail Region, KSA. Management in Health, 17, 31-36. 
[7] Kazancioğlu, R. (2013) Risk Factors for Chronic Kidney Disease: An Update. Kidney International Supplements, 3, 368-371. https://doi.org/10.1038/kisup.2013.79

[8] Ahmed, H.G., Ginawi, I.A. and Al-hazimi, A.M. (2014) Prevalence Estimates of Chronic Kidney Disease in Hail Region, KSA: In a Comprehensive Survey. International Journal of Science and Research (IJSR), 3, 252-256.

[9] Ginawi, I.A., Alasbali, A.M., Ahmed, H.G., et al. (2014) Prevalence Rates of Diabetes and Obesity in 4 Provinces in Hail Region, KSA. Egyptian Academic Journal of Biological Sciences, 6, 47-53.

[10] Alqurashi, K.A., Aljabri, K.S. and Bokhari, S.A. (2011) Prevalence of Diabetes Mellitus in a Saudicommunity. Annals of Saudi Medicine, 31, 19-23. https://doi.org/10.5144/0256-4947.2011.19

[11] Ahmed, H.G., Ginawi, I.A. and Al-hazimi, A.M. (2011) Prevalence of Hypertension in Hail Region, KSA: In a Comprehensive Survey. International Journal of Sciences. Basic and Applied Research (IJSBAR), 17, 288-296.

[12] Ahmed, H.G., Ginawi, I.A., Elasbali, A.M., Ashankyty, I.M. and Al-hazimi, A.M. (2014) Prevalence of Obesity in Hail Region, KSA: In a Comprehensive Survey. Journal of Obesity, 2014, Article ID: 961861.

[13] Streib, L. World's Fattest Countries, 2009-2012. https://www.forbes.com/2007/02/07/worlds-fattest-countries-forbeslife-cx_ls_0208 worldfat.html\#1fa0372264f1

[14] Kalaf, H., AlMesned, A., Soomro, T., Lasheen, W., Ewid, M. and Al-Mohaimeed, A.A. (2016) Cardiovascular Disease Risk Profile among Young Saudi Women of Al-Qassim, Saudi Arabia: A Cross-Sectional Study. International Journal of Health Sciences, 10, 29-37. https://doi.org/10.12816/0031214

[15] AlKhamees, O.A., AlNemer, K.A., Bin Maneea, A.W., AlSugair, F.A., AlEnizie, B.H. and Alharf, A.A. (2018) Top 10 Most Used Drugs in the Kingdom of Saudi Arabia 2010-2015. Saudi Pharmaceutical Journal, 26, 211-216.

https://doi.org/10.1016/j.jsps.2017.12.009 